\title{
Chalchiuhtotolin: LA GALLINA DE PIEDRA PRECIOSA Y LA CUEVA de La Chumpa, municipio de Jiquipilas, Chiapas
}

\author{
Thomas Arvol Lee Whiting
}

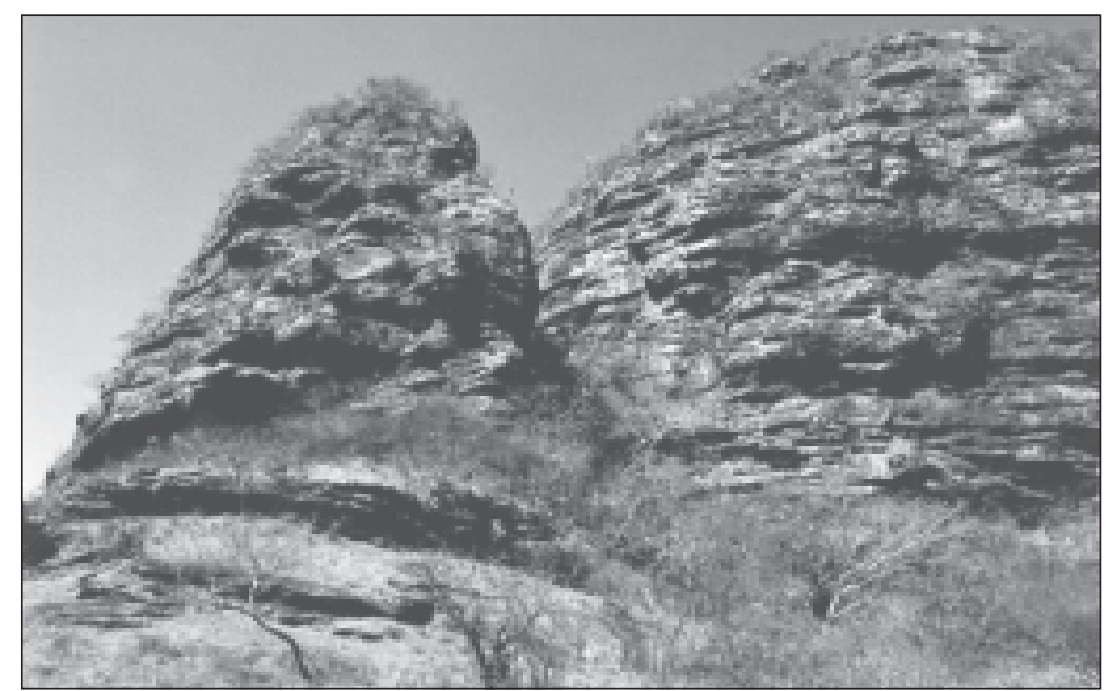

Figura 1. Cerro de La Chumpa donde se encuentra una cueva del mismo nombre en la cual los viejos sacerdotes zoques llevaban a cabo ritos propiciatorios para la lluvia, la fertilidad y la vegetación, dentro del sistema religioso prehispánico que funcionaba, aun atenuado, en el siglo XVII en Jiquipilas, Chiapas.

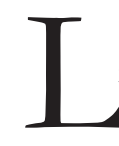

a Chumpa, cueva situada en un cerro del mismo nombre el cual se puede divisar desde el parque de Jiquipilas, Chiapas, localizado al otro lado del río La Venta, reconocido por los habitantes del municipio como encantado, figura en un juicio eclesiástico de brujos en el siglo XVII (fig. 1). La lectura de este juicio me despertó

Thomas Arvol Lee Whiting, CESMECA-UnICACH. el interés por considerar el rol del pavo doméstico en la cosmología mesoamericana (Aramoni, 1992).

Como lo ha reportado Dolores Aramoni, el obispo Núñez de la Vega en tal siglo enjuició a varios feligreses de Jiquipilas por ser brujos y estar involucrados en la adoración del demonio en una cueva del Cerro de La Chumpa, al sureste del pueblo; como mencionamos arriba (fig. 2). 
A B I E R T A

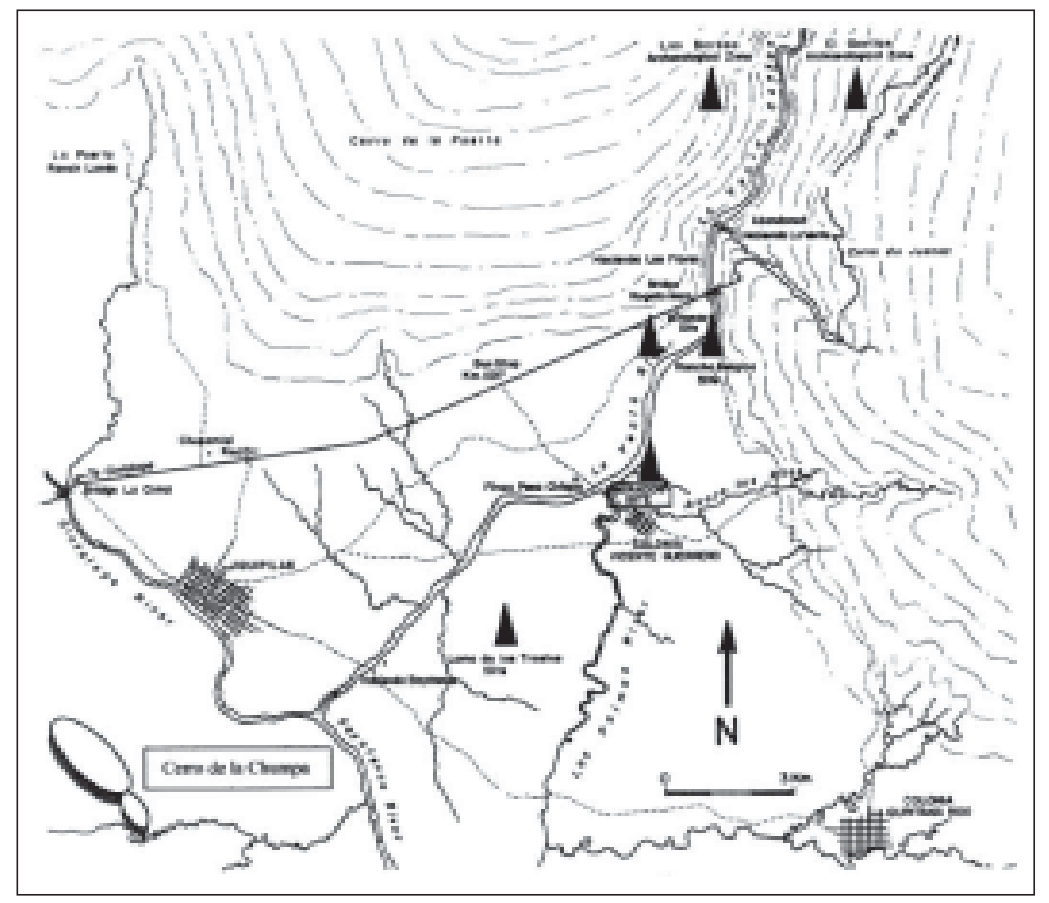

Figura 2. Región de Cintalapa y Jiquipilas, cuenca de los ríos Cintalapa, Soyotenco y La Venta. Localización de algunos sitios arqueológicos de importancia y del Cerro de La Chumpa.

La información que nos proporciona la etnohistoriadora, que procede de este juicio y su rico estudio del mismo, demuestra varios asuntos importantes, de los cuales sólo mencionaré tres que son relevantes para este artículo. Primero, el reconocimiento del Cerro de La Chumpa como lugar sagrado y propicio para actividades religiosas de la etnia zoque que habita el occidente de Chiapas. Segundo, el estudio profundo que presenta la etnohistoriadora de los ritos, las características y etimología de los nombres de los seres sobrenaturales quienes son objeto de los ritos, y de la tradición mesoamericana que remonta lejos en el tiempo, mucho antes del inicio de la conquista española. Tercero, que el pavo doméstico figura en el culto que se realizaba en el Cerro, el cual lleva por nombre local precisamente el de Chumpa, es decir, pavo o chompipi. (Aramoni, 1992). En Yucatán el pavo ocelado, ave silvestre, se llama cutr, ab kuts tso', chimpi, chumpipe, y chompipe (De la Garza, 1995: 113).

Otro antropólogo chiapaneco, Víctor Esponda, ha paleografiado el mismo legajo del juicio de los brujos (Esponda Jimeno, 2004: 95-142). Como colega y amigo mío, y conociendo mi interés por el cañón del río La Venta localizado a pocos kilómetros río abajo del Cerro La Chumpa, me propuso que fuéramos a buscar la cueva para considerar la posibilidad de excavación con el afán de aportar nuevos datos sobre el asunto del culto de los brujos jiquipiltecos. Debido a mis intereses arqueológicos respecto a la cuenca, así como por todo lo relacionado con la etnia zoque, me interesó de inmediato su invitación. Hemos ido en numerosas ocasiones a explorar el cerro en busca de la cueva, pero aún sin éxito. Este interés en La Chumpa, cueva y cerro, me ha llevado a buscar el porqué de este nombre y de 
la iconografía del ave doméstica como foco de atención ritual entre los antiguos zoques y otras etnias de Mesoamérica en general.

\section{Presencia del pavo doméstico en Mesoamérica}

El pavo domesticado en el Nuevo Mundo, Meleagris gallopavo L., Clase: Uccelli, Orden: Galliformi, Familia:
Meleagrididi, es el típico de varias especies de esta ave (Capocaccia Orsini; Doria y Doria, 1991: 68-73) (fig. 3); junto con el perro y la llama son los únicos animales domesticados por los habitantes del Nuevo Mundo. Con certeza, esta ave, cuyo punto de origen es México, es el único que fue domesticado en el Nuevo Mundo (Valle, 1947).

El pavo era considerado por los indios de Mesoamérica como ave sagrada y muy útil, además

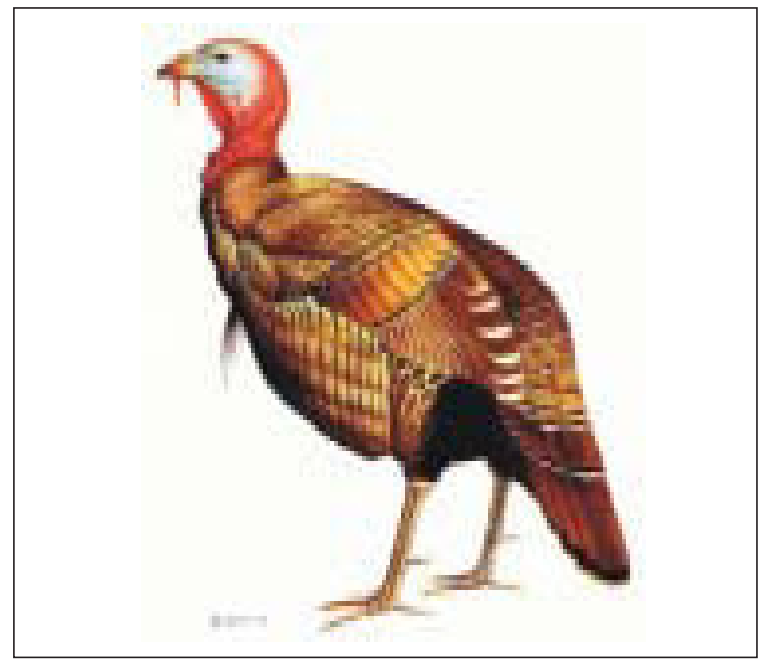

Figura 3. El pavo Meleagris gallopavo L. Es el tercer animal domesticado en el Nuevo Mundo después del perro y la llama.

de ser alimento, lo mismo que sus huevos. El ave comía langostas o chapulines, así lo relató Cortés en sus cartas al Rey Carlos V (Anónimo, 1933; Valle, 1947: 637, nota 5; Cortés, 1960). Esta tradición no se limita sólo a esta área cultural, sino que se encuentra ampliamente difundida mucho más al norte entre los zunis, navajos, así como entre ladinos de Arizona en la actualidad. Siendo yo joven solía apoyar a mi tío abuelo materno en pastorear parvadas de pavos jóvenes en los campos de alfalfa para que se alimentaran de los chapulines que a veces plagaban nuestro pueblo.

Parece que la primera noticia del pavo domesticado en el Nuevo Mundo, llamados guanajos, fue en Venezuela, donde Pedro Alonso Niño (citado por Valle, 1947: 638) los reportó en la costa de Cumaná en 1499. Este dato fue posteriormente confirmado por Grijalva, en la península de Yucatán, 1517.

El origen y la distribución del pavo han sido ampliamente discutidos por Valle en el trabajo citado arriba. Por esta razón y por falta de espacio no lo voy a resumir. Es pertinente recordar que en las crónicas españolas más tempranas se llamó "gallina" al pavo; por ejemplo, en Bernal Díaz del Castillo (Valle, 1947: 638-9). Más tarde, durante el resto de la época colonial, los pavos eran distinguidos de gallinas importadas de España con el apelativo "gallinas de la tierra". 
Al siempre venerable Fraile Bernardino de Sahagún es a quien le debemos la primera descripción local del pavo, realizada en 1527 :

...Las gallinas de esta tierra y los gallos se llama totolin. Son aves domésticas y conocidas, tienen la cola redonda, y plumas en las alas, aunque no vuelan; son de muy buen comer, la mejor carne de todas las aves; comen maíz mojado cuando pequeñas, y también bledos cocidos y molidos y otras yerbas; ponen huevos y sacan pollos. Son de diversos colores, unos blancos, otros rojos, otros negros, y otros pardos; los machos se llaman buexólotl y tienen gran papada y gran pechuga, tienen grandes presucesos, tienen unos corales colorados; la cabeza la tienen azul, en especial cuando se enojan, es sejunto [cejijunto]; tienen un pico de carne que le cuelga sobre el pico; bufa, hínchase, o enrízase. Los que quieren mal a otros dánlos a comer, o beber, aquel pico de carne blandujo que sobre el pico, para que no puede armar el miembro gentil.

La gallina hembra es menor que el gallo, es bajuela, tiene corales en la cabeza y en la garganta; tómase del gallo, pone huevos, échase sobre ellos y saca su pollos. Es muy sabrosa su carne, y gorda, es corpulenta, y sus pollos mételos debajo de sus alas, y dan a sus hijuelos de comer buscándoles gusanillos y otros cosas. Los huevos que concibe primeramente se cuajan y crían una telita. Y dentro crían su cáscaras tierna, y después les pone la gallina; después de puesto el huevo se endurece la cáscara (Sahagún, 1963: 53-54).

Una característica y actividad de los pavos macho que no dejan de mencionar los informantes aztecas es la de pasearse arrogantemente con las alas extendidas hasta el suelo mientras sacan aire de su buche con un fuerte soplido, así como su terca agresividad y la costumbre de atacar de carrera empujando a su contrincante con el pecho y pisando su pies para dominarlo, subiéndosele encima para pisarle el cuerpo (fig. 4). Hasta aquí dejamos la descripción natural del guajolote.

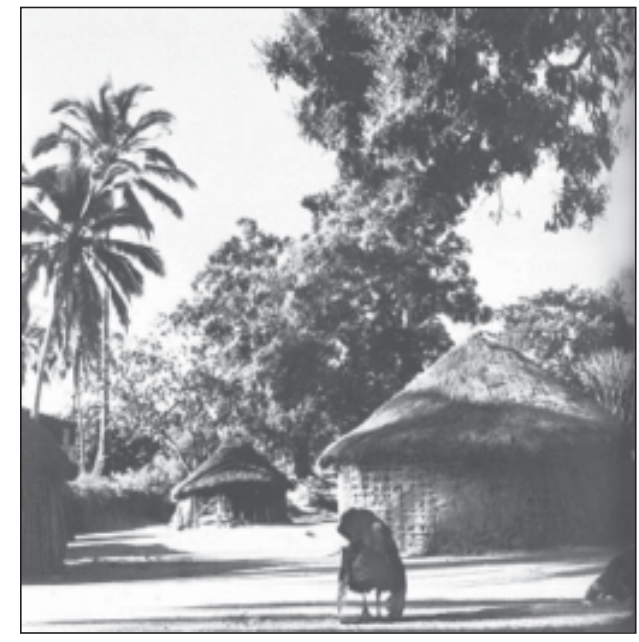

Figura 4. Pavo macho paseándose orgullosamente en el patio de una casa habitación.

\section{Etimología del nombre del cerro y la cueva, y tradición oral}

La toponimia del cerro y la cueva surgen, probablemente, del hecho que desde Jiquipilas el cerro parece una pavo echado con su distintiva y larga nuca y cabeza adelante del cuerpo formado por una esbelta y alta colina al este. El nombre común en Chiapas y Guatemala para el pavo doméstico es "Chompipi", que se deriva del sonido que hace el ave cuando comunica con otros de su misma especie. El termino Chumpa es una simplificación local del mismo nombre.

La tradición oral de Jiquipilas y de la región circundante a La Chumpa, le tiene mucho respeto al cerro. Mucha gente de los alrededores sencillamente no quiere hablar de ello, mucho menos ir a pasear por allá. Se cree que el cerro está encantado y suceden cosas raras a las personas que andan por esos rumbos. Para nosotros, lo raro es que durante nuestras andanzas por el lugar, no hemos encontrado una cueva de la envergadura que se señala en el juicio. 
En la tradición oral, relacionada con el pavo en Jiquipilas, se comenta que antes, durante los bailes del pueblo, llegaba ya tarde un hombre delgado y alto con un gran sombrero que le tapaba la cara. Las muchachas solían salir a bailar con él, pero se espantaban al darse cuenta que sus pies eran de pavo y al final salían huyendo abandonando al compañero fantasmagórico (Dolores Aramoni, comunicación personal, 2003).

\section{Presencia iconográfica del pavo americano en Mesoamérica}

No pretendo presentar aquí una discusión definitiva sobre la presencia iconográfica del pavo americano, pues no soy un especialista en la materia, sino sólo una muestra de lo más conocido y típico del pavo en Mesoamérica. La información gráfica sobre el pavo en esta área cultural proviene principalmente de materiales etnohistóricos, aunque también podemos tomar ejemplos de materiales textiles y cerámicos.

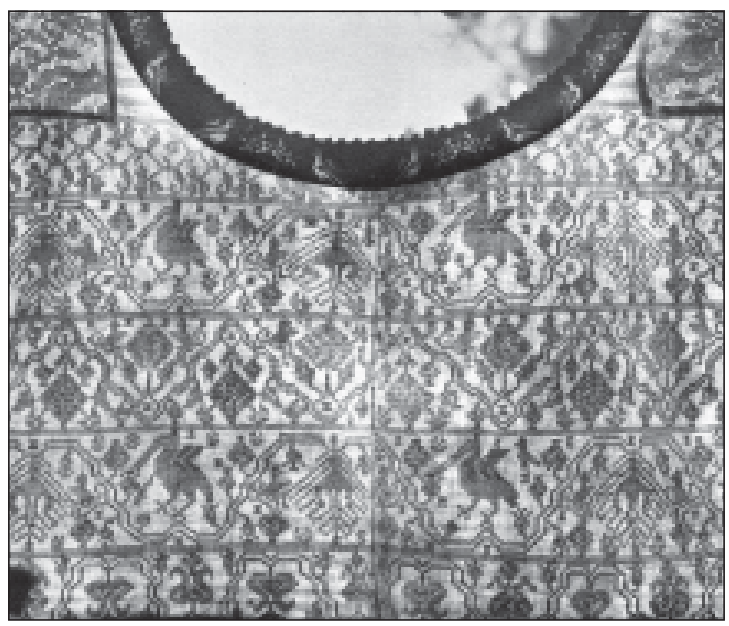

Figura 5. Huipil zoque con el pavo entre los elementos decorativos. Colectado y fotografiado por D. y D. Cordry en Ocozocoautla en 1940 (Cordry y Cordry, 1968, fig. 47).

\section{Ejemplos prehispánicos}

En el compendio del arte rupestre de Chiapas formado por Sophia Pincemin (1999) no se encuentra ni un pavo entre los más de 1,094 motivos de pintura y grabados sobre piedra en el estado durante las épocas pasadas.

Entre los elementos decorativos de textiles zoques de Tuxtla Gutiérrez y Ocozocoautla, Chiapas, hay pavos que aparecen en los huipiles del estilo renque, colectados y fotografiados por los Cordry (1968, fotografía 47; fig. 5) en los años cuarenta. Aquí el ave se encuentra frecuentemente como motivo decorativo. Un motivo diferente, pero de la misma ave, se aprecia en los textiles de los vecinos zapotecos.

Asimismo en la cerámica plomiza prehispánica del Soconusco, unos 1400 años antes, producida en una parte de la región, junto a la frontera con Guatemala; en el periodo Posclásico Temprano hay vasijas efigie de pavo que son particularmente bien elaboradas (fig. 6). Éstas fueron intercambiadas por los toltecas en todo Mesoamérica y aún fuera de ella (Lee, 1969). Shepard (1948: 105-112) registra siete ejemplares de esta cerámica

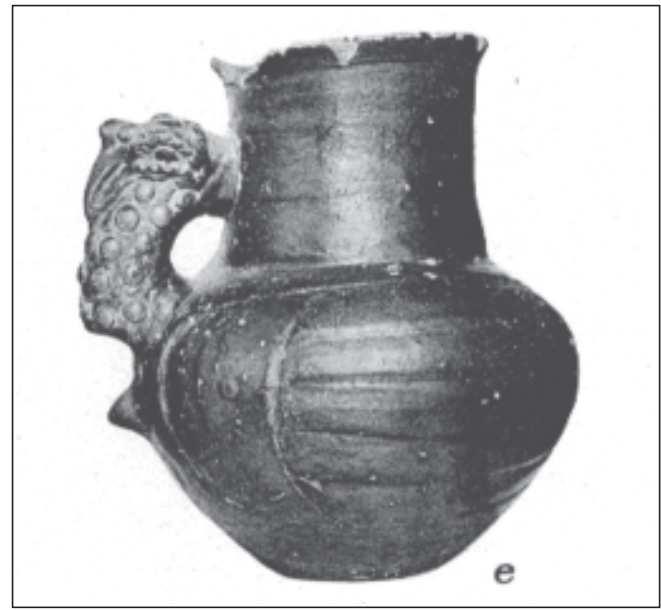

Figura 6. Vasija efigie de pavo en la vajilla Plomiza Tohil, hecho en México y Guatemala en un área limitada en la costa del Pacífico durante el Posclásico Temprano (Shepard, 1948, fig. 16, e). 
que se hallan en sitios arqueológicos dispersos entre Nayarit, en el norte, hasta el valle El Salitre de San Salvador, en el sur.

\section{Ejemplos etnográficos}

Los ejemplos etnográficos son tan abundantes en Mesoamérica que sólo mencionaré tres regiones del área maya próximas a la cuenca del río Soytenco o río La Venta, donde el pavo es ejemplo de un trato ritual especial.

Aún durante el siglo xx, en pueblos de las montañas Cuchumatanes de Guatemala como Santiago Chimaltenengo, era posible encontrar tres altares en los cerros más importantes cuyos guardianes, dioses protectores de la comunidad, "beben sangre de pavos" y queman incienso empapado de sangre de pavo (Wagley, 1957: 184).

En Todos Santos, los habitantes mam sacrifican pavos para untar la sangre en los bastones de los nuevos rezadores, además los sacrifican ante la Caja Real, así como en todas las fiestas de santos, en la cruces, en los cuatro cerros sagrados y unos 25 lugares sagrados más donde los rezadores hacen las visitas rituales (Oaks, 1969: 64, 66, 170, 209, 228, 230-2, 245, 247).

Los originarios de Jacaltenango llevaban a cabo una ceremonia, Canhampal, que tenía como objeto rezar frente a unas cruces y quemar la sangre de pavos sacrificados, recogida en las hojas interiores del maíz o totomoste (La Farge y Byers, 1931: 177-9). La carne de pavo sacrificado se cocinaba con maíz y pinole, y era consumida por los participantes.

Es una ceremonia parecida a la que existía entre los lacandones (Tozzer, 1913: 504-505), durante la cual la sangre de pavos sacrificados era quemada sobre ocote e incienso de copal.

En Pisté, Yucatán, los mayas hacen $u$ hanli col, comida ceremonial en la milpa para agradecer a los dioses por su cosecha. En esta ocasión sacrifican pavos que son cocidos y luego mezclados con frijoles, semillas de calabaza cocidas y molidas, formando con esta mezcla un bloque de trece tortillas en capas — en forma de pan de caja— (Steggerda, 1942: 57).

“... En suma, pavos domésticos o silvestres son hervidos y rostizados. Los riñones, el hígado, el corazón, el chaco y partes de la nuca y las alas se mantienen separados de las partes principales del ave y después los mezclan con el pan...” (Steggerda 1942: 57).

\section{Fuentes coloniales}

Entre los mayas yucatecos del siglo XVI, Landa reporta el sacrificio de pavos como rito de cacería al dios de la misma actividad. Rito que tenía como propósito asegurar el éxito en la caza (Tozzer, 1941: 155, nota 769).

En 1562, Juan Uc “...mató una pava cuya sangre puso sobre la nariz, la cara y la frente de los ídolos, y ungió en nombre del dios de la caza, a quien llaman Agueche..." (Tozzer, 1941:155). La ofrenda de la cabeza de una pava y la unción de la sangre a las imágenes es mencionada varias veces por Landa, para diferentes dioses y ritos, por ejemplo, la estatua de Kjnich Ahau, Chac Acautun, Ek, Sac y Uayeb, este último, patrón de los cinco días nefastos al final del año solar (Tozzer, 1941: 144, 145 146, notas 662, 701 y 719; ver también God N, Kelly, 1977: 72).

\section{Códices}

En los códices mayas el pavo se proyecta más como comida de sacrificio que como animal que proporciona su sangre y su cabeza a ofrendas (fig. 7). El glifo del ave se ve en el códice Dresde en cuatro páginas de manera normal junto con el glifo de Kan o maize (Lee, 1985: 23b, 28c, 30b y 41c). De igual manera se ve en el códice Madrid un glifo de pavo en seis páginas (Lee, 1985: 8, 104b, 105b, 106c, 107b y 109b).

En los códices del centro de México de la tradición mexica se encuentran algunas representaciones que nos permiten aproximarnos un poco más al significado de la iconografía del pavo en la cosmología de Mesoamérica. 
A B I E R T A

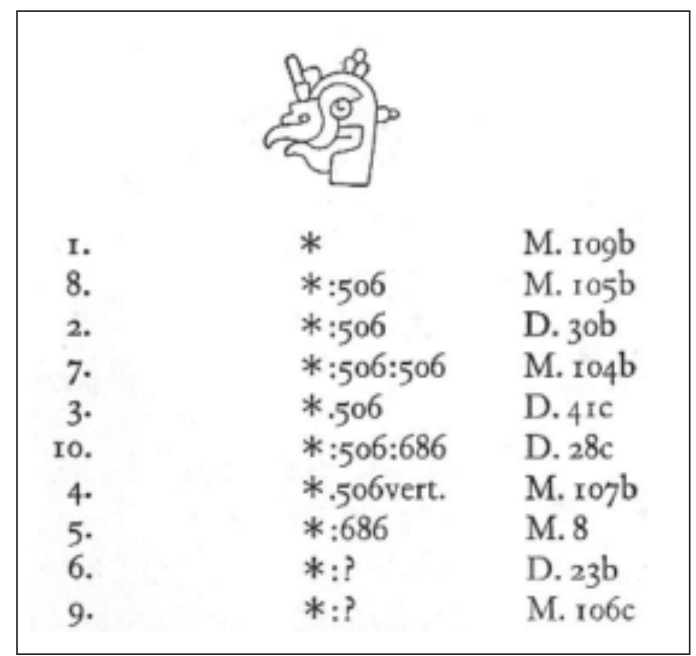

Figura 7. Glifo 839, de pavo en los códices Mayas Dresde y Madrid (Thompson, 1962: 391).

Estos códices se tratan de los llamados tonalámatl o códices augurales de los destinos de los hombres (Tudela de la Orden, 1980; fig.8).

En el códice Borbónico encontramos que el patrón de la decimoséptima trecena del calendario sagrado es una persona representando a la deidad Tezcatlipoca (Quiñones Keber, 1995: 185), pero vestido con el plumaje de un pavo y asociado con el signo del día Cé Atlo "Uno Agua", el día en que termina la trecena (Paso y Troncoso, 1980: 75); su nombre, Chalchiuhtotolin, se traduce como "gallina de piedra preciosa”, que es una metáfora para la sangre de autosacrificio. El símbolo de preciosidad se encuentra en el dibujo del moco de pavo. Además el pavo trae otros dos símbolos especiales: uno, el copete de estrellas; el otro, el espejo humeante. También en su espalda hay un adorno de papeles donde se encuentra pintado Tláloc, dios de la lluvia. Para reforzar la idea de la lluvia o líquido hay en la escena agua que cae desde una gran olla.

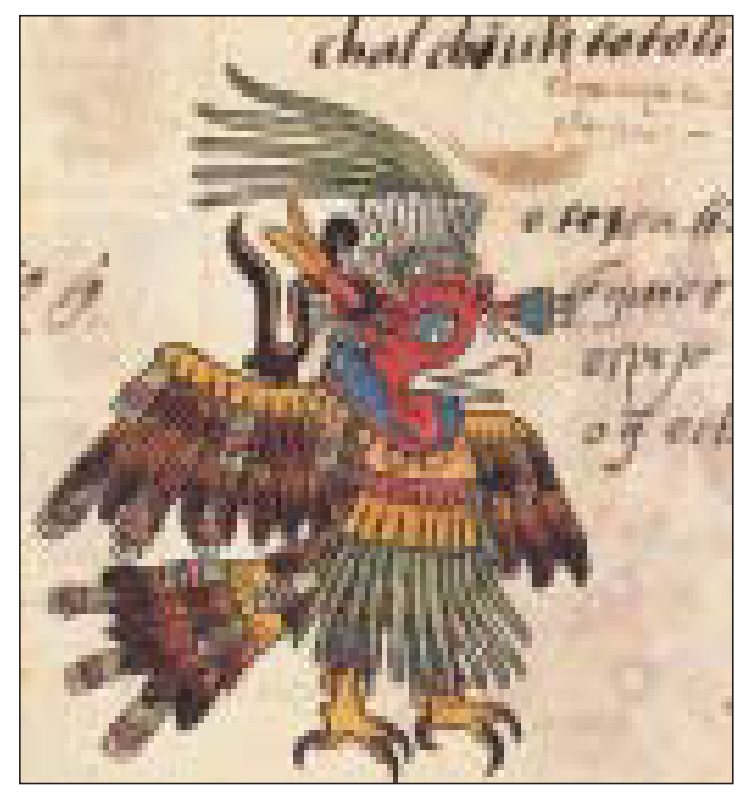

Figura 8. Pintura del pavo del códice Tudela (Tudela de la Orden, 1980: 99, 310).

En el códice Vaticano B, sección dedicada a "los señores de los veinte días" del calendario en el día 18, Pedernal, tiene como su patrón precisamente Chalchiuhtotolin, guajolote enjoyado o "pavo de jade» que es otra manifestación de Tezcatlipoca y representa el auto sacrificio y el ayuno, a decir de Anders y Jansen (1993: tira 93; 352). La relación entre el patrón del día que simboliza la sangre del auto sacrificio y el día pedernal, piedra de sacrificio, no podría ser más clara.

En otra sección del mismo códice Vaticano B, vemos que el Chalchiuhtotolin es uno de los nueve bebedores divinos del pulque y está adornado en forma de Envoltorio Sagrado (Anders y Jansen, 1993: 286, 305, 307; fig. 9). Este códice repite más o menos lo que aprendimos sobre Chalchiuhtotolin como patrón de la decimoséptima trecena del calendario sagrado en el códice Borbónico. Quiñones Keber (1995: 185) ha dicho que este ejemplo es la "representación de un pavo fantásticamente adornado y entronado, sin símbolos claros de Tezcatlipoca", masculino. 
En el códice Telleriano-Remensis, en el verso del folio 20 se encuentra la descripción de la $17^{a}$. trecena del calendario sagrado una vez más, pero con varios símbolos de Tezcatlipoca. Se encuentran los símbolos principales de la misma deidad a su lado, el espejo humeante cerca de la cabeza y el tocado de plumas de garza, ambos asociados íntimamente con la deidad (Quiñones Keber, 1995: 185; fig.10).

En el códice Tudela hay una hora, la Novena, de las trece en que está dividido el día, la cual tiene el pavo como agorero, Chalchiuhtotoli (Tudela de la Orden, 1980: 184). Además el estudio dice que "El pavo suele llevar el disfraz del dios de la vegetación que es Xipetotec y como su plumaje es ocelado - con manchas blancas - es semejante al cielo estrellado, por esto fue el ave de sacrificios" (1980: 184).

En el códice Borgia, 17a. sección del tonalámatl, se encuentra el Chalchiuhtotolin, "gallina de piedra preciosa" de acuerdo con Seler (1963: 11:223), quien agrega que es símbolo de Tezcatlipoca (Fig. 11).

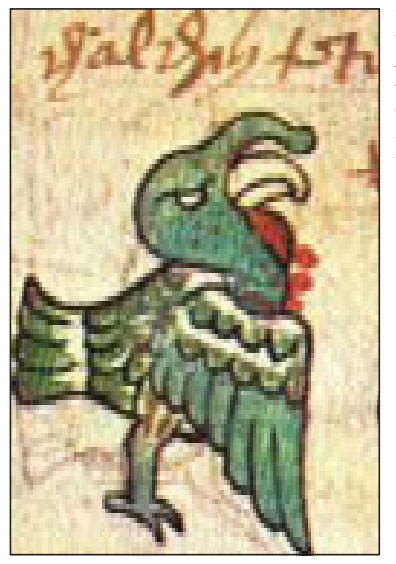

Figura 9. Chalchiuhtotolin, patrón de la XVII trecena del calendario sagrado (Quiñones Keber, 1995: 44, 185).

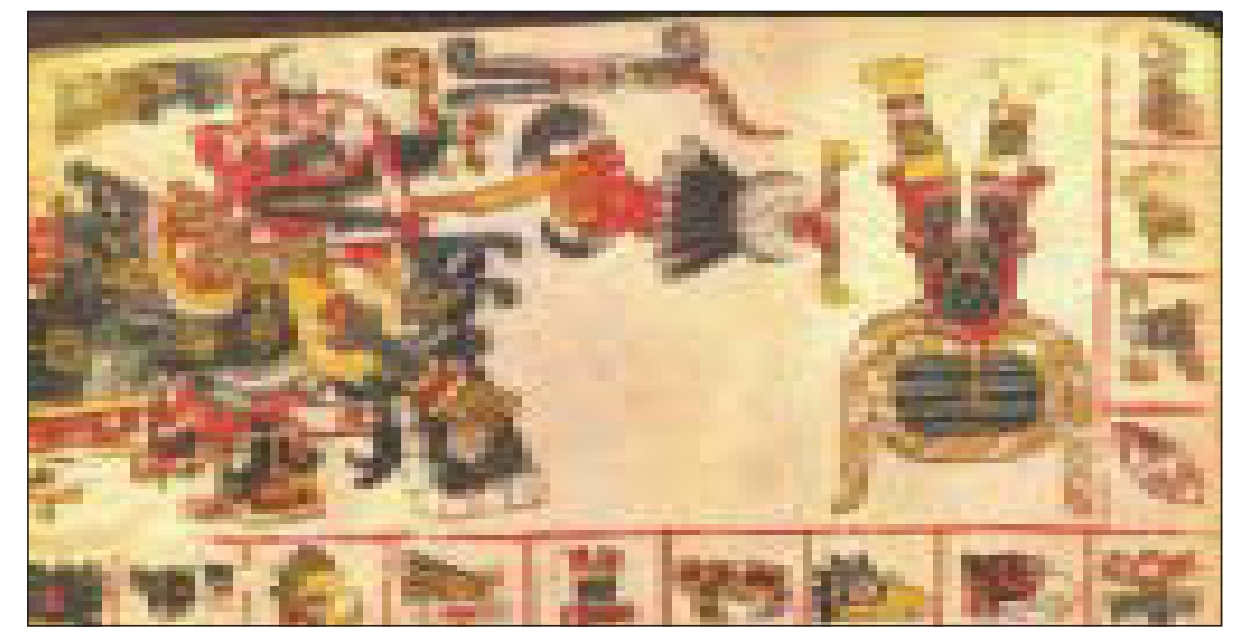

Figura 10. "Pavo de jade", Chalchiuhtotolin, patrón del xviII día del calendario sagrado, día Pedernal, otra manifestación de Tezcatlipoca (Anders y Jensen, 1993: 93).

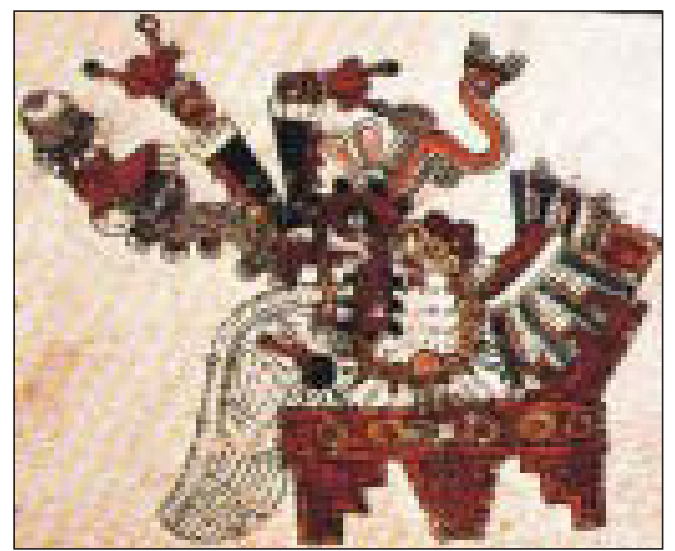

Figura 11. Chalchiutotolin, el XVIII día del tonalámatl o calendario sagrado de 260 días del códice Borgia (Seler, 1963: 11). 
También dice Seler (1963: 1: 150-151) que "el pavo representa el agua, sobre todo el chalchiúhatl, el agua preciosa, es decir, el líquido precioso del autosacrificio, o sea, la sangre" (fig. 12). Al entregar la sangre de un autosacrificio al Chalchiuhtotolin como ofrenda, por medio de la pata de un águila, la sangre lava la suciedad del pecado de quien lo lleva a cabo. La imagen es un pavo lujosamente adornado y entronado (Quiñones Keber, 1995:185).

\section{Significados del pavo en la cosmología mesoamericana}

Chalchiuhtotolin es símbolo de agua, pero no sólo agua de lluvia como Tláloc, sino agua preciosa, sangre que los penitentes extraían en los ejercicios de autosacrificio.
Este ejercicio se refuerza en su relación con el día pedernal, piedra de sacrificio. El motivo del pedernal es una punta de lanza ancha que tiene una cara con ojos, cejas y dientes claramente indicados.

La piedra muerde literalmente la carne humana en el proceso de autosacrificio. La piedra es la personificación de su función porque, como una cosa viva, se hace sentir al entrar y deja una herida dolorosa de la cual no es posible olvidarse en muchos días.

El autosacrificio significa e implica algo más que sólo sacrificar sangre. En la época prehispánica de Mesoamérica fueron hechos sacrificios diariamente a cautivos de guerra o esclavos u otros personas compradas para esta fin. Esta actividad era normal y necesaria cosmológicamente, pero impersonal, no afectaba más que a la víctima; era, pues, ajena al

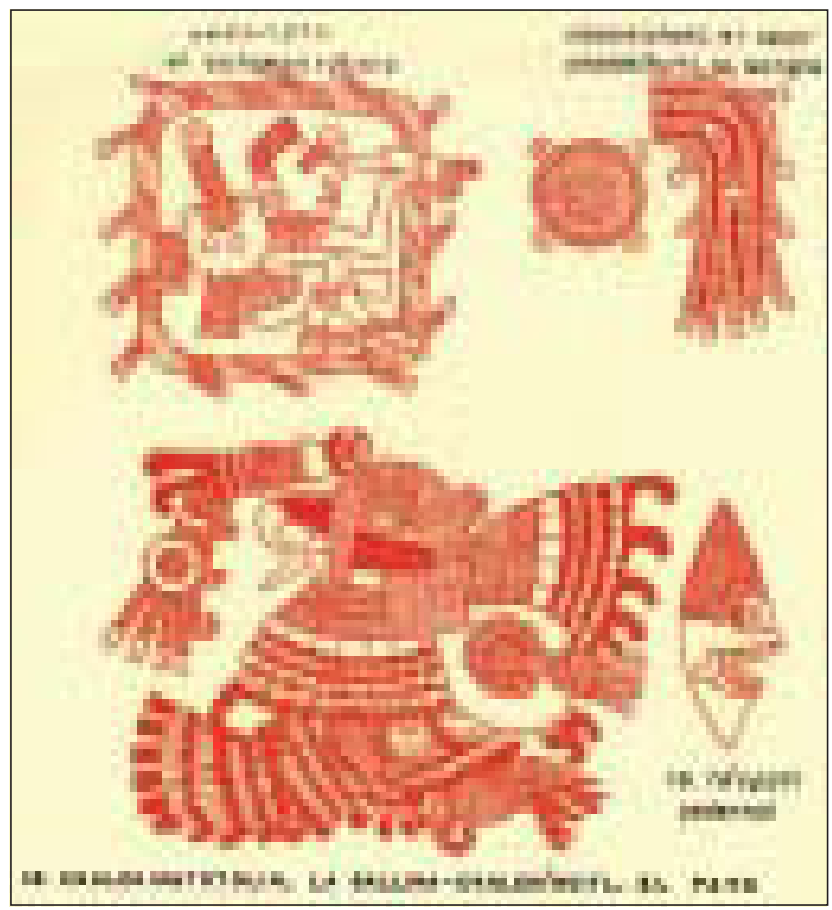

Figura 12. El Chachiutotolin, el XvIII día del tonalámatl, símbolo de Tezcatlipoca. Como pavo representa la sangre de autosacrificio (Seler, 1963, comentario 64). 
individuo. El autosacrificio, por otra parte, constituía un acto personal, íntimo y abnegado. Si la sangre era necesaria para alimentar a los dioses, la sangre dada voluntariamente por la propia mano de la persona que hacía la ofrenda, resultaba ser de máximo valor, ya que era dada voluntariamente y con espíritu de abnegación. De este concepto divino proviene lo sagrado del pavo como símbolo de sangre de autosacrificio y su estrecha relación con lo más sagrado de la cosmología antigua y Tescatlipoca, dios supremo Mesoamericano.

\section{Conclusiones}

El pavo es alimento, pero especialmente alimento ceremonial por excelencia. Sacrificar el pavo al dios Chalchiuhtotolin lo convertía en alimento divino, tal como resultaba con los cuerpos humanos sacrificados corporativamente por los sacerdotes de la comunidad. Era alimento que nutría no sólo el cuerpo, también el espíritu y el alma. Tanto entre los mayas como entre los mexicas el pavo fue consumido como algo divino y considerado de mucho provecho para el individuo, en cuanto fortalecía su relación con el cosmos.

El pavo es la única ave doméstica en Mesoamérica y el Nuevo Mundo que con sus grandes cantidades de sangre servía para embarrar objetos ceremoniales como bastones, altares, imágenes, incienso, incensarios y otros objetos; hacerlo era untarlos con el mismo líquido vital del dios Chalchiuhtotolin. Obra mágica para los creyentes, ya que era alimento divino para fortalecer, nutrir y sostener la gracia divina del mismo dios.

Pero, ¿por qué el humilde pavo fue escogido para personificar la magnanimidad del auto sacrificio? Nadie sabe, quizá nunca lo sabremos, pero tal vez fue por su carácter real y noble, por su porte reconocido por todos como el ave señorial del patio. El hecho de no tener mucho con qué defenderse lo hizo siempre aparecer con el papel de víctima, aunque los pavos sean reconocidos como necios y valientes, pues son capaces de atacar a perros, gallos, niños y hasta adultos. Tal vez fue la cabeza y el "moco" rojo del pavo macho que llamó la atención de los sacerdotes antiguos y lo asociaron con la sangre y por ello fue incluido dentro del calendario sagrado como deidad especial.

Se puede concluir con la idea de que la asociación del pavo con el numen principal entre los mexicas, Tezcatlipoca, demuestra su posición alta en la cosmología mesoamericana a pesar de su limitada presencia en la misma, y que la sangre de autosacrificio, representada por Chalchiuhtotolin, era la máxima ofrenda, ya que indirectamente se ofrendaba también al dios Tezcatlipoca de manera personal.

\section{Bibliografía}

Anders, Ferdinando y Maarten Cansen, 1993, Manual del Adivino. libro explicativo del llamado Códice Vaticano B con facsimilar, Introducción y explicación, Serie Códices Mexicanas IV, Sociedad Estatal Quinto Centenario (España), abrodanische Druckund Verlagranstalt, (Austria) y Fondo de Cultura Económica (México).

Anónimo, 1933, "Navajos fight grasshoppers with turkeys", en New York Times, 6 de agosto, New York.

Aramoni, Dolores, 1992, Los refugios de lo sagrado: religiosidad, conflicto y resistencia entre los roques de Chiapas, Consejo Nacional Para la Cultura y Las Artes, México.

Capocaccia Orsini, Lilia, Giorigo Doria y Giuliano Doria, 1991, 1492-1992. Animali e Piante dalle Americhe all Europa SAGEP Editorice, Genova.

Cordry, Donald Bush \& Dorothy M. Cordry, 1941, Costumes and Weaving of the Zoque Indians of Chiapas, México, Southwest Museum Papers, Num. 15, Southwest Museum, Los Angeles.

Cortés, Hernán, 1960, Cartas de Relación, Editorial Porrúa, S.A., Colección Sepan Cuantos 7, México.

De la Garza, Mercedes, 1995, Aves sagradas de los mayas, México, Facultad de Filosofía y Letras, Centro de Estudios Mayas, Universidad Nacional Autónoma de México. México.

Esponda Jimeno, Víctor Manuel, 2004, "Autos contra Antonio Ovando, indio del pueblo de las Xiquipilas, Nicholas de Santiago, mulato libre, vecino de el y Roque Martin, indio de Tuxtla, por hechiceros, brujos, nagualistas y 
supersticiosos", en Nuevas perspectivas sobre el castigo de la herodoxcia indigena en Nueva España: siglos XVI-XVII, coordinación de Ana de Zeballa Bascoechea, Servicio Editorial de la Universidad del País Vasco. Bilbao, pp. 95142.

Kelly, David Humiston, 1977, Deciphering the Maya Script, University of Texas Press. Austin.

La Farge, Oliver y Douglas Byers, 1931, The Year Bearer's People, Middle American Research Series, Publication No. 3, The Tulane University of Louisiana, New Orleans.

Lee, Thomas A., Jr., 1978, «The Origin and Development of Plumbate Ware», Revista Mexicana de Estudios Antropológicos. Tomo xxiv, Núm. 3, Sociedad Mexicana de Antropología. México, pp. 287-300.

—, 1985, Los códices mayas, Universidad Autónoma de Chiapas, México.

Oaks, Maude, 1969, The Two Crosses of Todos Santos, Bollingen, Series XxVII, Princeton University. Princeton.

Paso y Troncoso, Francisco del, 1980, Descripción. historia y exposición del Códice Borbónico (edición facsimilar), comentario explicativo de E. T. Hamy, Siglo Veintiuno Editores, S.A., México.

Pincemin, Sophia, 1999, De manos y soles: estudio de la gráfica rupestre en Chiapas, Universidad de Ciencias y Artes de Chiapas, Tuxtla Gutiérrez.

Quiñónez Keber, Eloise,1995, Codex Telleriano-Remensis. University of Texas Press. Austin.

Sahagún, Fr. Bernardino de, 1963, Florentino Codice. Book 11 Earthly: Things, Translación del azteca al inglés por Charles
E. Dibble y Arthur J. O. Anderson, The School of American Research y The University of Utah, Santa Fe y Salt Lake City.

Seler, Eduard, 1990-1993, Eduard Seler: Collected Works in Mesoamerica Linguistica and Archeology, 4 Vols., Frank E. Comparato, general editor, Labyrinthos, Calver City.

Shepard, Anna O., 1948, Plumbate: a Mesoamerican Trade Ware, Publication 573, Carnegie, Institution of Washington. Washington, D. C.

Steggenda, Morris, 1942, Maya Indians of Yucatan, Carnegie Institution of Washington, Publication 531. Washington, D. C.

Tozzer, Alfred, 1913, A Spanish Manuscript Letter on the Lacandones in the Archives of the Indias at Seville, XVIII International Congreso of Americanists, 1912, Parte II, London, pp. 497-509.

—, 1941 Landa's Relación de las Cosas de Yucatán: a translation. Papers of the Peabodv Museum of American Archaeologv and Ethnology, Vol. XVIII, Harvard University, Cambridge.

Tudela de la Orden, José, 1980, Códice Tudela, Ediciones Cultural Hispánica. Madrid.

Valle, Rafael Heliodoro, 1947, "Anales del mole de guajolote", en Vigesimoséptimo Congreso de Americanistas, Actas de la primera sesión celebrada en la Ciudad de México en 1939, Tomo II, Instituto Nacional de Antropología e Historia. SEP. México, pp. 637-648.

Wagley, Charles, 1957, Santiago Chimaltenango, Seminario de Integración Social Guatemalteca, Pule, Núm. 4, Ciudad de Guatemala. 